\title{
Electrical Double-Layer and lon Bridging Forces between Symmetric and Asymmetric Charged Surfaces in the Presence of Mono- and Divalent lons
}

\author{
Liu, Xiaoyan; Feilberg, Karen Louise; Yan, Wei; Stenby, Erling Halfdan; Thormann, Esben
}

Published in:

Langmuir

Link to article, DOI:

10.1021/acs.langmuir.7b00450

Publication date:

2017

Document Version

Peer reviewed version

Link back to DTU Orbit

Citation (APA):

Liu, X., Feilberg, K. L., Yan, W., Stenby, E. H., \& Thormann, E. (2017). Electrical Double-Layer and lon Bridging Forces between Symmetric and Asymmetric Charged Surfaces in the Presence of Mono- and Divalent lons. Langmuir, 33(18), 4426-4434. https://doi.org/10.1021/acs.langmuir.7b00450

\section{General rights}

Copyright and moral rights for the publications made accessible in the public portal are retained by the authors and/or other copyright owners and it is a condition of accessing publications that users recognise and abide by the legal requirements associated with these rights.

- Users may download and print one copy of any publication from the public portal for the purpose of private study or research.

- You may not further distribute the material or use it for any profit-making activity or commercial gain

- You may freely distribute the URL identifying the publication in the public portal 


\title{
Electrical double-layer and ion bridging forces between symmetric and asymmetric charged surfaces in the presence of mono- and divalent ions
}

\author{
Xiaoyan Liu ${ }^{1,2}$, Karen L. Feilberg ${ }^{2}$, Wei Yan $^{1}$, Erling H. Stenby ${ }^{1}$, Esben Thormann ${ }^{1 *}$ \\ ${ }^{1}$ Department of Chemistry, Technical University of Denmark, Kemitorvet 206, 2800 Kongens \\ Lyngby, Denmark \\ ${ }^{2}$ Centre for Oil and Gas - Technical University of Denmark, Elektrovej 375, 2800 Kongens \\ Lyngby, Denmark \\ * Corresponding author at: Department of Chemistry, Technical University of Denmark, \\ Kemitorvet 206, 2800, Kgs. Lyngby, Denmark, tel: +45 452524 39, email: esth@kemi.dtu.dk
}

\begin{abstract}
An atomic force microscope, employing the colloidal probe technique, was used to study the interactions between six different combinations of silane functionalized silica surfaces in $\mathrm{NaCl}$ and $\mathrm{CaCl}_{2}$ solutions. The surfaces consisted of monolayers of the apolar trimethoxy(octyl)silane, the positively charged (3-aminopropyl)trimethoxysilane and the negatively charged (3mercaptopropyl)trimethoxysilane. The interactions between the three symmetric systems, as well as between the three asymmetric combinations of surfaces, were measured and compared to calculated electrical double-layer forces. The results demonstrated that the long-range interactions between the surfaces in all cases were dominated by double-layer forces, while short-range interactions, including adhesion, were dominated by ion bridging forces in the cases where both interaction surfaces favored adsorption of calcium ions. The study thus also demonstrates how surface force studies in mono- and divalent salt solutions can be used as an analytical tool for probing specific functional groups on heterogeneous surfaces.
\end{abstract}

\section{Introduction}

Interactions between charged surfaces are of vital importance for the interpretation of numerous phenomena, ${ }^{1}$ such as clay swelling, ${ }^{2,3}$ colloid stability, ${ }^{4,5,6}$ bio-membrane interactions ${ }^{7}$ and biological systems involving dissimilar surfaces. To a first approximation, the interactions between surfaces in many such systems are described by the DLVO theory, which includes electrical double-layer forces and van der Waals forces. ${ }^{8,9}$ In this study, the strength and range of the van der Waals force is determined by the material properties, i.e., the dielectric properties, of the interacting surfaces and the media. However, for the electrical double-layer force, both the range and the magnitude are strongly dependent on the concentration and type of added ions. The strength of the double-layer force is determined by the surface charge densities and the surface potentials while the range is determined by the ionic strength. All these properties are affected by the addition of salt. However, beside the DLVO forces, the interaction between complex surfaces can also be affected by hydrophobic forces, hydration forces, polymer bridge forces and ion bridging forces. ${ }^{10}$ Here in particular, ion bridging forces will be dependent on the polarizability and valency of the added ions. ${ }^{11 \text {, }}$ 


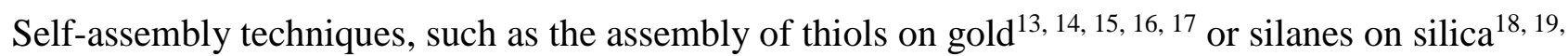
$20,21,22$, have been extensively used to fabricate monolayers with various functional terminal groups on different kinds of surfaces. In this study, we have made silane based monolayers of trimethoxy(octyl)silane, (3-aminopropyl)trimethoxysilane, and (3-mercaptopropyl)trimethoxysilane on silica microparticles attached to silica particles on atomic force microscopy cantilevers and on flat silica substrates by vapor-phase silanization. The three different monolayers represent surfaces of different hydrophobicity/hydrophilicity and of different charge, and the surface structures were characterized by atomic force microscopy (AFM) imaging and by contact angle measurements. By the atomic force microscope colloidal probe technique $23,24,25$ the interactions between the different surfaces in monovalent and divalent electrolyte solutions are investigated and compared to calculated electrical double-layer forces. By comparing the interactions between symmetric systems (similar surfaces) and asymmetric systems (dissimilar surfaces) surface potentials, surface charge densities and the degree of surface charge regulation is estimated. Moreover, we also discuss adhesion forces between the different surface pairs in order to demonstrate how the presence of divalent ions can alter the interaction depending on the pairing of different functional groups on the two interacting surfaces. Finally we also discuss the existence of an inner and an outer charge layers and their effects on the ion induced bridging forces.

\section{Materials and Methods}

Materials. Electrolyte solutions were made by dissolving sodium chloride $(\mathrm{NaCl}, 99.5 \%$, SigmaAldrich) or calcium chloride $\left(\mathrm{CaCl}_{2}, 96 \%\right.$, anhydrous, Sigma-Aldrich) in ion-exchanged water from a Milli-ROPls unit connected to a Milli-Q plus 185 system and filtered through a $0.2 \mu \mathrm{m}$ Millipak filter at $25{ }^{\circ} \mathrm{C}$. The resistivity of the purified water was $18.2 \mathrm{M} \Omega \mathrm{cm}$, and the organic content was less than $3 \mathrm{ppb}$. Trimethoxy(octyl)silane (96\%), (3-aminopropyl)trimethoxysilane (APTES, 99\%), and (3-mercaptopropyl)trimethoxysilane (95\%) were purchased from Sigma-Aldrich, Denmark. Thermally oxidized silicon wafers with a $100 \mathrm{~nm}$ thick $\mathrm{SiO}_{2}$ layer were purchased from WaferNet, Inc. USA. Silica particles with a diameter of approximately $15 \mu \mathrm{m}$, used for the colloidal probe measurements, were purchased from Kisker Biotech, Germany. Rectangular silicon cantilevers (NSC15/Al BS, MikroMasch, Estonia) were used for atomic force microscope (AFM) image measurements. Rectangular tipless cantilevers (CSC37/TIPLESS/Cr-Au, MikroMasch, Estonia) with the approximate dimensions of $250 \mu \mathrm{m}$ in length, $32.5 \mu \mathrm{m}$ in width, and normal spring constants approximately $0.09 \mathrm{~N} / \mathrm{m}$ were used for AFM force measurements. The spring constants of the cantilevers were determined by the Sader method ${ }^{26,27}$ before attaching the silica particles on the cantilevers.

Preparation of silane based monolayers on silica surfaces and silica particles. A silica particle was glued to the end of the cantilever with the assistance of an Eppendorf Micromanipulator (PatchMan NP 2), a Nikon Eclipse LV100ND microscope and a small amount of epoxy glue (Araldite, Rapid). The exact size of the particles was determined using a Nikon Eclipse LV100ND microscope, employing image analysis with Infinity Analyzer (Lumenera Corporation). The cantilevers with silica particles and the cut, sized, bare silica surfaces were cleaned in plasma (Harrick PDC-3XG, New York) for 40 seconds. After plasma cleaning, the cantilevers with silica particles and the silica surfaces were immediately transferred to a vacuum desiccator containing $0.5 \mathrm{ml}$ of either trimethoxy(octyl)silane, (3-aminopropyl)trimethoxysilane, or (3-mercaptopropyl)trimethoxysilane in 
a separate open vessel. The silane based monolayers, which are schematically illustrated in Figure 1 and which from now on will just refer to as $\mathrm{C} 8, \mathrm{NH}_{2}$ or $\mathrm{SH}$, respectively, were prepared by vapor phase deposition in a desiccator by using a vacuum pump for a few minutes to reduce pressure. The deposition time was 24 hours. After the deposition, the modified silica surfaces and the cantilevers were cleaned with toluene several times, followed by rinsing with ethanol several times, and then gently blow-dried with compressed air. The prepared silica surfaces and silica particles were used for AFM force measurements immediately after preparation.

A
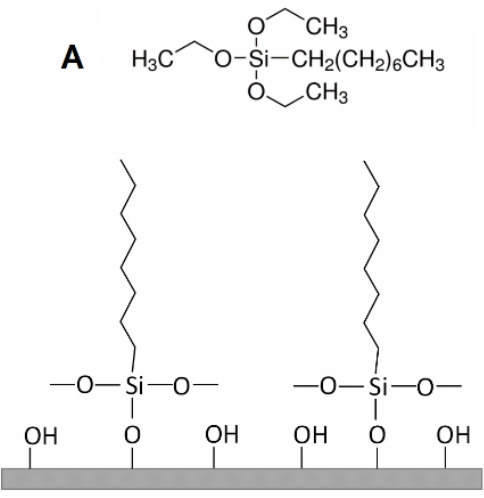

B $\mathrm{H}_{3} \mathrm{CO}-\stackrel{\substack{\mathrm{S} \\ \mathrm{O}}-\mathrm{CH}_{3}}{\mathrm{OCH}_{3}} \sim \mathrm{NH}_{2}$

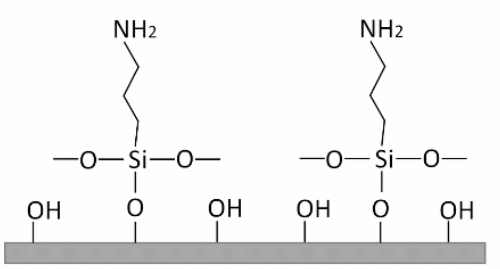

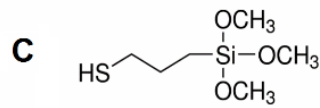

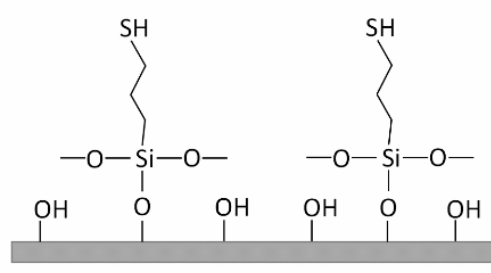

Figure 1. Molecular structure of trimethoxy(octyl)silane (C8) (A), (3-aminopropyl)trimethoxysilane $\left(\mathrm{NH}_{2}\right)(\mathrm{B})$, and (3-mercaptopropyl)trimethoxysilane $(\mathrm{SH})(\mathrm{C})$, and the corresponding schematic illustration of the silanes on silica on the bottom.

Surface characterization. The contact angles of a water droplet placed on the bare silica surfaces and on silica surfaces modified by silanes were determined at the liquid-solid-air interface assessed by the sessile drop method at room temperature using an Attension Theta Lite tensiometer (Biolin Scientific, Finland). The water droplet (with a volume of $1 \mu \mathrm{L}$ ) was placed at the surfaces by a Hamilton syringe, and images of the droplet shape were obtained by a CCD-camera. The contact angles were then determined by fitting the Young-Laplace equation to the profile of the droplet. The reported contact angles were obtained at static conditions and are the mean values of the left and right contact angles.

Images of the bare silica surface, the silica surfaces modified by silanes and the bare silica micro particle used for colloidal probe measurements, were determined by using a NanoWizard 3 AFM atomic force microscope (JPK instrument, Germany), operated in air using tapping mode. The surfaces were imaged using a scan size of $1 \times 1 \mu \mathrm{m}^{2}\left(500 \times 500 \mathrm{~nm}^{2}\right.$ for the silica micro particle). The JPK SPM data processing software was employed to analyze the recorded images.

Surface forces. The force versus distance between silane modified silica probes and silane modified silica surfaces were measured by the atomic force microscope colloidal probe technique. Before each experiment, the cantilever holder, O-rings and all other tools were cleaned by immersion in $2 \%$ Hellmanex (Hellma $\mathrm{GmbH})$ solution for approximately 1 hour. They were then rinsed several times with Milli-Q water and blow-dried with compressed air. The surface forces between the six different surface pairs $\left(\mathrm{C} 8-\mathrm{C} 8, \mathrm{C} 8-\mathrm{NH}_{2}, \mathrm{C} 8-\mathrm{SH}, \mathrm{NH}_{2}-\mathrm{NH}_{2}, \mathrm{SH}-\mathrm{SH}\right.$ and $\mathrm{SH}-\mathrm{NH}_{2}$ ) were measured in $1 \mathrm{mM}$ $\mathrm{NaCl}$ and in $1 \mathrm{mM} \mathrm{CaCl}_{2}$. The $\mathrm{pH}$ of the solutions were measured with a $827 \mathrm{pH}$ lab (Metrohm, 
Switzerland). The $\mathrm{pH}$ of $1 \mathrm{mM} \mathrm{NaCl}$ and in $1 \mathrm{mM} \mathrm{CaCl}_{2}$ are 5.69 and 5.64, respectively. All surface force measurements were performed at a constant approach and separation velocity of $2 \mu \mathrm{m} / \mathrm{s}$, and to check for possible surface inhomogeneities and local effects, 70 force curves were recorded in each case at a regular spacing over a $2 \times 2 \mu \mathrm{m}^{2}$ area. The reproducibility of consecutive force curves are demonstrated in Figure S3 and S4 in the supporting information.

DLVO calculations. The DLVO theory is based on the assumption that the total force between colloidal particles is the sum of the electrical double-layer force and the van der Waals forces and is employed to explain colloidal stability in aqueous media and how stability is affected by the addition of salt. ${ }^{8}$ The theoretical electrostatic double-layer force was calculated within the non-linear Poisson-Boltzmann approximation using either constant charge or constant potential boundary conditions. Since no analytical solutions exist for the non-linear Poisson-Boltzmann equation numerical solutions are found through a stepwise process. The procedure for these calculation is described in detail elsewhere. ${ }^{28}$ In addition to the electrical double-layer force, the van der Waals force between the spherical probe and the flat surface was calculated as ${ }^{10}$

$$
F=\frac{A R}{6 D^{2}}
$$

where $A$ is the Hamaker constant and $D$ is the surface separation. For silica surfaces in electrolyte solutions a non-retarded Hamaker constant of $6.3 \times 10^{-21} \mathrm{~J}$ has previously been used ${ }^{29}$. However, as will be discussed later, surface roughness will effectively suppress the effective van der Waals force measured over a separation distance similar to the magnitude of the amplitude roughness parameter. 30

Comparisons between experimentally obtained force-distance curves and DLVO calculations thus allow us to determine the surface potentials and surface charge densities at large separation.

\section{Results and Discussion}

\subsection{Surface characterization}

AFM topographical images of the surfaces are shown in Figure 2. While certain structures are observed at the nanometer scale, the surfaces appear homogeneous on larger length scales. Further, a roughness analysis reveals that all surface layers have a similar degree of smoothness as the uncoated silica substrate (see Table 1). Thus, although a degree of polymerization might be expected in the silanization process, ${ }^{31,32,33}$ no larger structures are formed on the surfaces. However, while the three different monolayer surfaces appear rather similar from the topography images, water contact angle measurements reveal their different surface chemistry (see values in Table 1). The C8 surface is characterized by the highest contact angle value due to the apolar nature of the alkyl chains, while the $\mathrm{NH}_{2}$ and $\mathrm{SH}$ surfaces are more hydrophilic due to expected ionization of the functional groups. The surface of the silica micro particle used for the colloidal probe measurements was also imaged by AFM (see Figure S1 in the supporting information). After flattening of the image to correct for the surface curvature the $\mathrm{R}_{\mathrm{q}}$-value was determined to approximately $6 \mathrm{~nm}$ which as expected is 
significantly higher than the roughness of the oxidized silicon wafer. This is important for our further analysis since it recently has been demonstrated that surface roughness can significantly affect the appearance of the surface forces measured by the colloidal probe technique. ${ }^{30}$ For our case, it mean that the van der Waal forces will be suppress since the effective plane of zero separation will be located cannot be reached due to hard-wall repulsion between surface asperities of the probe and the flat surface. The electrical double layer force will not be affected in the same way as this force is more long-ranged. However, we note that the surface roughness might also influence the appearance on the electrical double layer force at short separations.
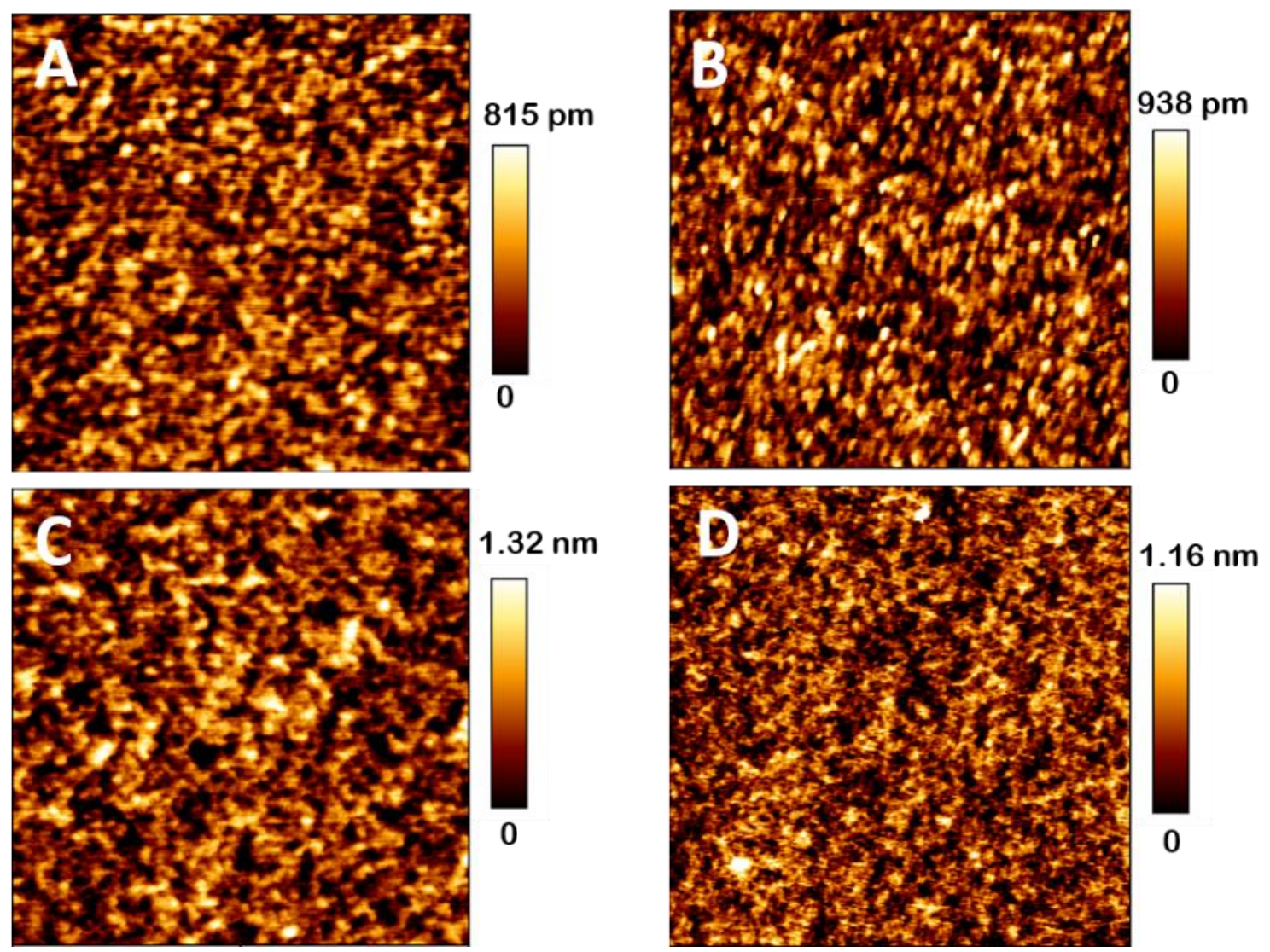

Figure 2. AFM topographical images of bare silica (A), $\mathrm{C} 8$ (B), $\mathrm{NH}_{2}(\mathrm{C})$ and $\mathrm{SH}$ (D) recorded in air. The image size is $1 \times 1 \mu \mathrm{m}^{2}$.

Table 1. Surface roughness $(\mathrm{Rq})$ values determined by AFM tapping mode in air and water contact angles determined by the sessile drop method at room temperature for bare and silanized silica surfaces.

\begin{tabular}{|l|c|c|c|c|}
\hline & Silica & $\mathrm{C} 8$ & $\mathrm{NH}_{2}$ & $\mathrm{SH}$ \\
\hline $\mathrm{Rq}(\mathrm{nm})$ & 0.18 & 0.21 & 0.25 & 0.26 \\
\hline Water contact angle $\left(^{\circ}\right)$ & $26 \pm 1$ & $82.6 \pm 1$ & $64 \pm 2$ & $47.5 \pm 3$ \\
\hline
\end{tabular}

\subsection{Surface forces}


By employing the AFM colloidal probe technique, we have measured the surface forces between the six combinations of surfaces with different surface chemistry $\left(\mathrm{C} 8-\mathrm{C} 8, \mathrm{NH}_{2}-\mathrm{NH}_{2}, \mathrm{SH}-\mathrm{SH}, \mathrm{C} 8-\mathrm{NH}_{2}\right.$, $\mathrm{C} 8-\mathrm{SH}, \mathrm{SH}-\mathrm{NH}_{2}$ ) in $1 \mathrm{mM} \mathrm{NaCl}$ and in $1 \mathrm{mM} \mathrm{CaCl}_{2}$. In the following sections we will discuss the forces measured on approach (non-contact forces) and on separation (adhesion) and in the two different salt solutions separately, before summarizing the different results.

\subsubsection{Non-contact forces in $\mathrm{NaCl}$}

Figure 3 shows representative approach force curves for the six combinations of surfaces, measured in the $1 \mathrm{mM} \mathrm{NaCl}$ solution. The force curves are, in each case, presented together with the calculated electrical double-layer force, which assume either constant charge (red curves) or constant potential (blue curves) boundary conditions. The Debye lengths $\left(\kappa^{-1}\right)$, surface potentials $(\psi)$, and surface charge densities $(\sigma)$ of the surfaces used for the electrical double-layer force calculations in each case are presented in Table 2. 

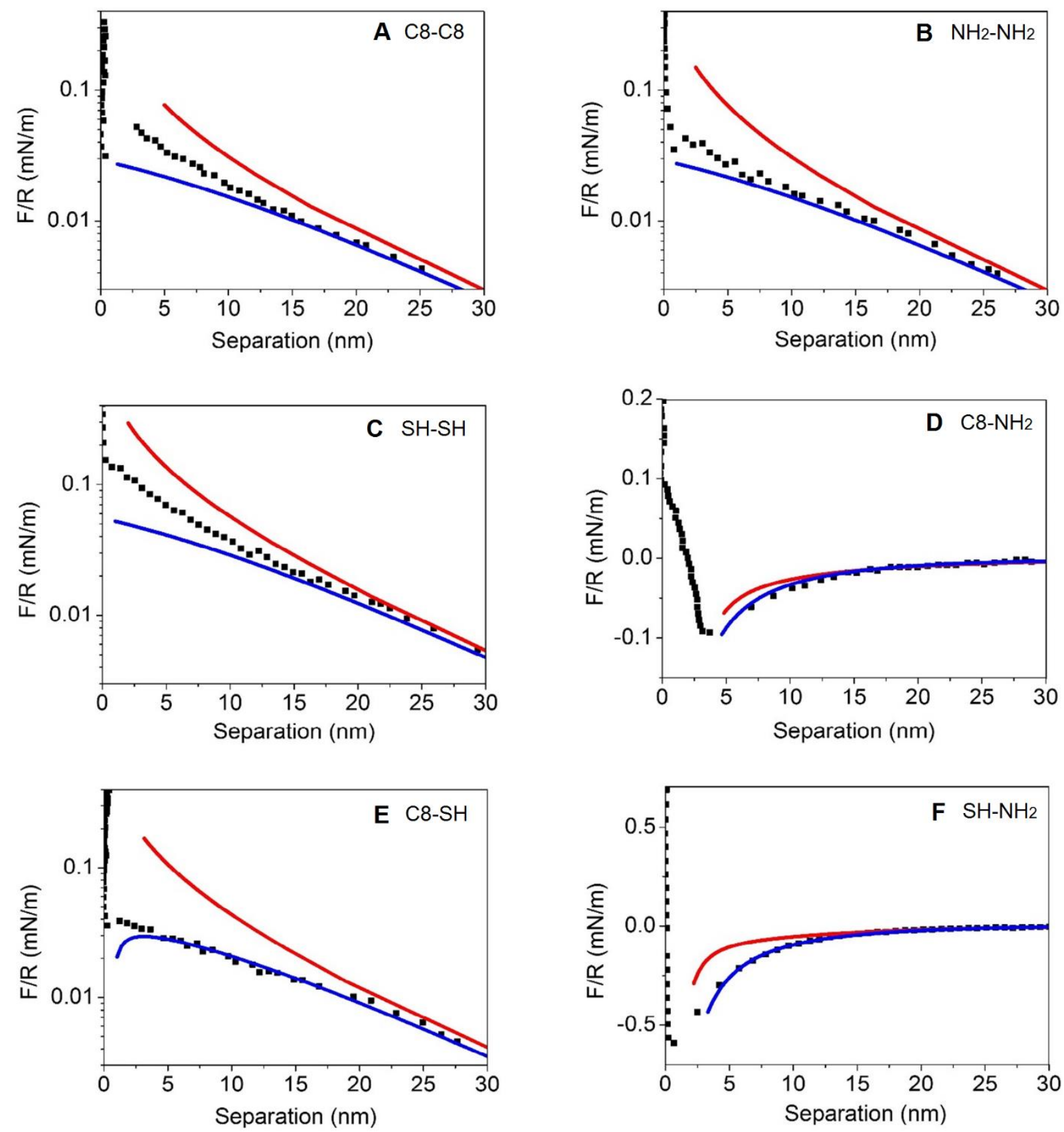

Figure 3. Force normalized by radius as a function of separation between silane modified silica particle and silane modified silica surface for C8-C8 (A), $\mathrm{NH}_{2}-\mathrm{NH}_{2}$ (B), $\mathrm{SH}-\mathrm{SH}$ (C), C8- $\mathrm{NH}_{2}$ (D), C8-SH (E), $\mathrm{SH}_{-} \mathrm{NH}_{2}$ (F) across $1 \mathrm{mM} \mathrm{NaCl}$. Black symbols represent data obtained on approach. The upper red and lower blue lines are the fitted electrical double-layer force using constant charge and constant potential boundary conditions, respectively. The fitted Debye-length of $9.6 \mathrm{~nm}$ corresponds to a salt concentration of $1 \times 10^{-3} \mathrm{M}$ (1:1 electrolyte). 
Table 2. Parameters used in electrical double-layer force calculation of surfaces in $1 \mathrm{mM} \mathrm{NaCl}$

\begin{tabular}{|l|c|c|c|c|c|c|c|c|c|}
\hline & $\mathrm{C} 8-\mathrm{C} 8$ & $\mathrm{NH}_{2}-\mathrm{NH}_{2}$ & $\mathrm{SH}-\mathrm{SH}$ & \multicolumn{2}{|c|}{$\mathrm{C} 8-\mathrm{NH}_{2}$} & \multicolumn{2}{c|}{$\mathrm{C} 8-\mathrm{SH}$} & \multicolumn{2}{c|}{$\mathrm{SH}^{*}$} \\
\cline { 2 - 10 } & $\mathrm{C} 8$ & $\mathrm{NH}_{2}$ & $\mathrm{SH}$ & $\mathrm{C} 8$ & $\mathrm{NH}_{2}$ & $\mathrm{C} 8$ & $\mathrm{SH}$ & $\mathrm{SH}$ & $\mathrm{NH}_{2}$ \\
\hline$\kappa^{-1}(\mathrm{~nm})$ & 9.6 & 9.6 & 9.6 & 9.6 & 9.6 & 9.6 & 9.6 & 9.6 & 9.6 \\
\hline$\psi(\mathrm{mV})$ & -8 & +8 & -11 & -8 & +8 & -8 & -11 & -14 & +14 \\
\hline$\sigma\left(\mathrm{C} / \mathrm{m}^{2}\right)$ & $5.8 \times 10^{-4}$ & $5.8 \times 10^{-4}$ & $8.0 \times 10^{-4}$ & $5.8 \times 10^{-4}$ & $5.8 \times 10^{-4}$ & $5.8 \times 10^{-4}$ & $8.0 \times 10^{-4}$ & $1.0 \times 10^{-3}$ & $1.0 \times 10^{-3}$ \\
\hline
\end{tabular}

The results in Figure 3A, B and $\mathrm{C}$ show the forces between the symmetric systems, $\mathrm{C} 8-\mathrm{C} 8, \mathrm{NH}_{2}-\mathrm{NH}_{2}$, and $\mathrm{SH}-\mathrm{SH}$. The $\mathrm{NH}_{2}-\mathrm{NH}_{2}$ and $\mathrm{SH}-\mathrm{SH}$ systems show a long-ranged repulsion over the entire range of interactions, while the $\mathrm{C} 8-\mathrm{C} 8$ shows a long-ranged repulsion and a short-ranged attraction, where the latter is interpreted as a hydrophobic attraction between the alkyl chains. ${ }^{34,}{ }^{35}$ However, for all three cases, the long-ranged repulsion fits electrical double-layer interactions, and due to the symmetric nature of the systems, the double-layer forces can be calculated by a single value of the surface potential in each case. It should be noted that we solely based on fittings of double-layer forces for the symmetric systems cannot determine whether a surface potential is positive or negative. However, when coupled with knowledge about the chemical composition of the surface groups and the measurements of the asymmetric systems the signs are for the studied surfaces are easily deduce. By this approach, we find that the $\mathrm{C} 8$ surface has a surface potential of $-8 \mathrm{mV}$ and a surface charge density of $5.8 \times 10^{-4} \mathrm{C} / \mathrm{m}^{2}$, and we suggest that this surface charge originates from the dissociation of unreacted hydroxyl groups on the silica surfaces. When compared to the surface potential and surface charge density, $-44 \mathrm{mV} 3.6 \times 10^{-3} \mathrm{C} / \mathrm{m}^{2}$, respectively, obtain for the interaction between bare silica surfaces (see Figure S2 in the supporting information), it suggest that 10-20\% of the hydroxyl groups remains after the silanization step. For the $\mathrm{NH}_{2}-\mathrm{NH}_{2}$ system and the $\mathrm{SH}-\mathrm{SH}$ system, our measurements reveal effective surface potentials of $+8 \mathrm{mV}$ and $-11 \mathrm{mV}$ and effective surface charge densities of $5.8 \times 10^{-4}$ and $8.0 \times 10^{-4} \mathrm{C} / \mathrm{m}^{2}$, respectively. It should here be noted that for the $\mathrm{NH}_{2}$ surfaces and the SH surfaces, we term these properties as effective surface potentials and effective surface charge densities, respectively, since we are aware that these surfaces might be composed of both charges originating from dissociation of unreacted hydroxyl groups on the silica surfaces (as for the $\mathrm{C} 8$ surfaces) and of charges from ionization of the functional groups $\left(\mathrm{NH}_{2}\right.$ and $\left.\mathrm{SH}\right)$. As it will become clear later, it appears to make a difference whether the charges are located at the silica surface or among the functional groups. Here, we thus refer to the charges localized near the silica surfaces as the inner charged layer and to the charges originating from ionization of $\mathrm{NH}_{2}$ and $\mathrm{SH}$ as the outer charged layer.

Figure 3D, E and $\mathrm{F}$ show the forces between the asymmetric systems, $\mathrm{C} 8-\mathrm{NH}_{2}, \mathrm{C} 8-\mathrm{SH}$ and $\mathrm{SH}-\mathrm{NH}_{2}$. For the $\mathrm{C} 8-\mathrm{NH}_{2}$ system we observed a long-ranged attractive force in qualitative agreement with the predictions for electrical double-layer forces between oppositely charged surfaces. Further, the electrical double-layer force calculations fits with surface potentials of $-8 \mathrm{mV}$ and $+8 \mathrm{mV}$, which are identical to the values found in the corresponding symmetric systems. For the C8-SH system we observed a long-ranged repulsive force in qualitative agreement with the predictions for a doublelayer force between dissimilar surfaces with surface potential of the same sign. Again, the electrical double-layer force calculations fits with values of the surface potentials that are identical to the values 
found in the corresponding symmetric systems. Finally, for the $\mathrm{SH}-\mathrm{NH}_{2}$ system we observe a longranged attractive force that is in qualitative agreement with the predictions for the double-layer force between dissimilar surfaces with surface potential of the opposite sign. Here, the electrical doublelayer force calculation reveals values of the effective surface potentials of $-14 \mathrm{mV}$ and $+14 \mathrm{mV}$, respectively, which corresponds to an effective surface charge densities of $1.0 \times 10^{-3} \mathrm{C} / \mathrm{m}^{2}$ for both surfaces. In contrast to the $\mathrm{C} 8-\mathrm{SH}$ and the $\mathrm{C} 8-\mathrm{NH}_{2}$ systems, these values are both significantly higher than the values found in the corresponding symmetric system, and it is thus clear that the SH surface is becoming more negatively charged and that the $\mathrm{NH}_{2}$ surface is becoming more positively charged relative to what we observed for the symmetric systems. Such an extra charge regulation mechanism is further in agreement with another observation from Figure 3F, namely, that the experimental force curve seems to be much better described with the constant potential boundary conditions than by the constant charge boundary conditions. ${ }^{36}$ Since we do not observe this extra strong charge regulation for the $\mathrm{C} 8-\mathrm{NH}_{2}$ system, which also showed an attractive double-layer force, we suggest that this is due to the different ability for charge regulations in the inner and in the outer charge layers. The negative charges on the $\mathrm{C} 8$ surface are localized behind the alkyl chains near the silica surface, which apparently hampers charge regulation. Oppositely, the result for the $\mathrm{SH}-\mathrm{NH}_{2}$ system indicates that charge regulation is more likely to occur for two surfaces with outer charged layers.

\subsubsection{Non-contact forces in $\mathrm{CaCl}_{2}$}

Figure 4 shows representative approach force curves for the six combinations of surfaces, measured in $1 \mathrm{mM} \mathrm{CaCl}_{2}$ solution. In each case, the force curves are presented together with calculated electrical double-layer force, which assume either constant charge (red curves) or constant potential (blue curves) boundary conditions, and the parameters from the electrical double-layer force calculations are presented in Table 3. 

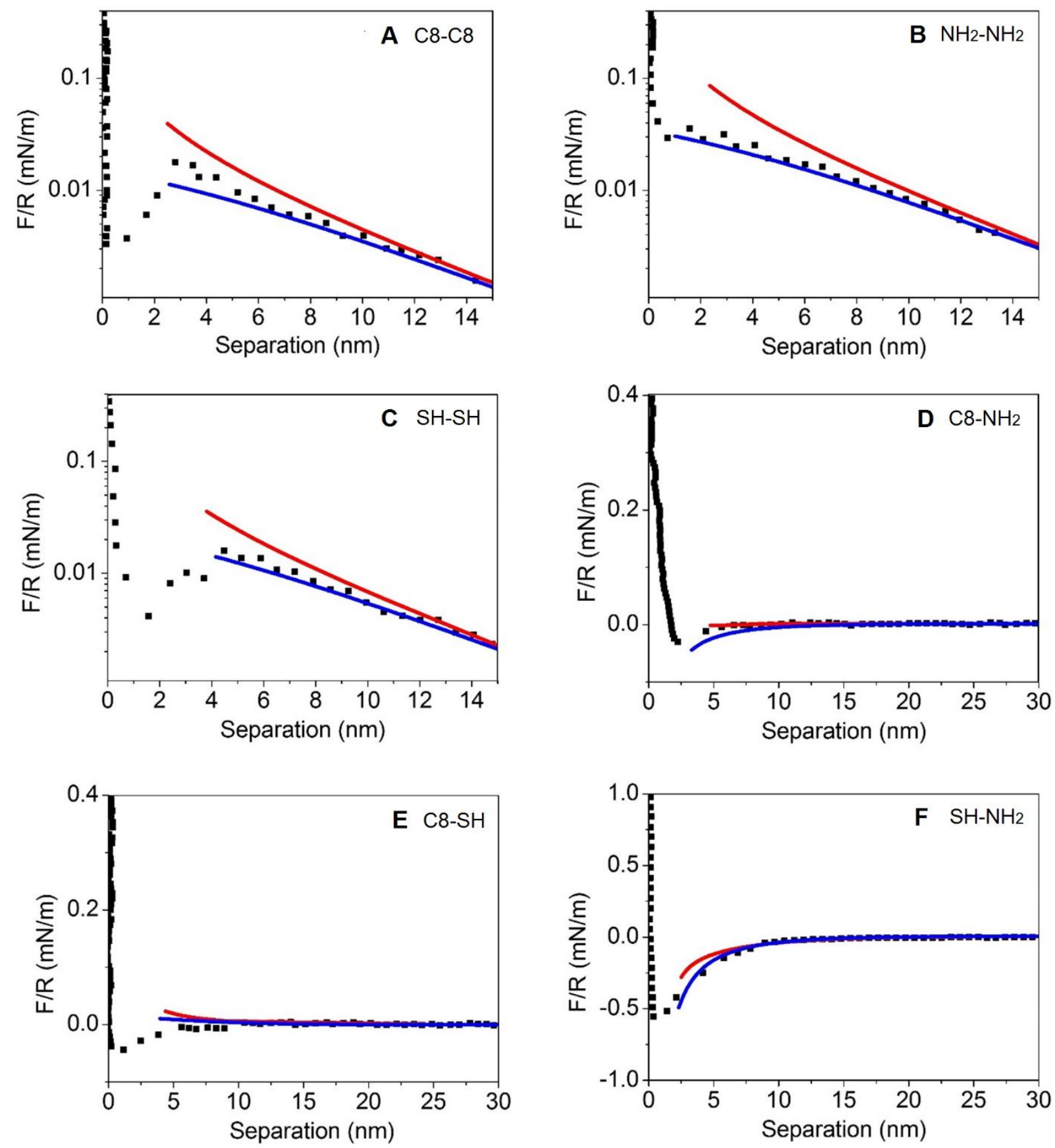

Figure 4. Force normalized by radius as a function of separation between silane modified silica particle and silane modified silica surface: C8-C8 (A), $\mathrm{NH}_{2}-\mathrm{NH}_{2}$ (B), $\mathrm{SH}-\mathrm{SH}(\mathrm{C}), \mathrm{C} 8-\mathrm{NH}_{2}$ (D), C8$\mathrm{SH}(\mathrm{E}), \mathrm{SH}-\mathrm{NH}_{2}(\mathrm{~F})$ across $1 \mathrm{mM} \mathrm{CaCl}$. Black symbols represent data obtained on approach. The upper red and lower blue lines are the fitted electrical double-layer force using constant charge and constant potential boundary conditions, respectively. The fitted Debye-length of $5.6 \mathrm{~nm}$ corresponds to a salt concentration of $1 \times 10^{-3} \mathrm{M}$ (2:1 electrolyte).

Table 3. Parameters used in electrical double-layer force calculation of surfaces in $1 \mathrm{mM} \mathrm{CaCl}_{2}$ 


\begin{tabular}{|l|c|c|c|c|c|c|c|c|c|}
\hline & $\mathrm{C} 8-\mathrm{C} 8$ & $\mathrm{NH}_{2}-\mathrm{NH}_{2}$ & $\mathrm{SH}-\mathrm{SH}$ & \multicolumn{2}{|c|}{$\mathrm{C} 8-\mathrm{NH}_{2}$} & \multicolumn{2}{c|}{$\mathrm{C} 8-\mathrm{SH}$} & \multicolumn{2}{c|}{$\mathrm{SH}-\mathrm{NH}_{2}$} \\
\cline { 2 - 10 } & $\mathrm{C} 8$ & $\mathrm{NH}_{2}$ & $\mathrm{SH}$ & $\mathrm{C} 8$ & $\mathrm{NH}_{2}$ & $\mathrm{C} 8$ & $\mathrm{SH}$ & $\mathrm{SH}$ & $\mathrm{NH}_{2}$ \\
\hline$\kappa^{-1}(\mathrm{~nm})$ & 5.6 & 5.6 & 5.6 & 5.6 & 5.6 & 5.6 & 5.6 & 5.6 & 5.6 \\
\hline$\psi(\mathrm{mV})$ & -4 & +6 & -5 & -4 & +6 & -4 & -5 & -13 & +13 \\
\hline$\sigma\left(\mathrm{C}^{2} \mathrm{~m}^{2}\right)$ & $3.9 \times 10^{-4}$ & $5.8 \times 10^{-4}$ & $4.8 \times 10^{-4}$ & $3.9 \times 10^{-4}$ & $5.8 \times 10^{-4}$ & $3.9 \times 10^{-4}$ & $4.8 \times 10^{-4}$ & $7.3 \times 10^{-4}$ & $7.3 \times 10^{-4}$ \\
\hline
\end{tabular}

Before describing the measured forces in the six different situations, we will briefly discuss how changing the salt from $\mathrm{NaCl}$ to $\mathrm{CaCl}_{2}$ can change the long-ranged and short-ranged forces between charged surfaces. Compared to a monovalent ion, $\mathrm{Ca}^{2+}$ will be more prone to adsorb to a negatively charged surface and have the ability to reduce, or even reverse, the effective surface charge. ${ }^{37}$ Thus for our systems, the addition of $\mathrm{Ca}^{2+}$ could potentially have an effect on the $\mathrm{C} 8$ and the $\mathrm{SH}$ surfaces, which are both negatively charged but also potentially on the $\mathrm{NH}_{2}$ surface, which is expected to carry negative charges in the inner charge layer and positive charges in the outer charge layer. Finally, slightly lower surface potentials are expected in $1 \mathrm{mM} \mathrm{CaCl}_{2}$ compared to in $1 \mathrm{mM} \mathrm{NaCl}$ due to the higher ionic strength. All of the above mentioned effects are thus expected to lead to weaker longranged double-layer forces. Finally, with respect to short-ranged forces, it is expected that shortranged attractive ion bridging forces can occur between two surfaces that both are prone to adsorption of $\mathrm{Ca}^{2+}$ ions. With this in mind, we will now discuss our experimental results.

Figure $4 \mathrm{~A}, \mathrm{~B}$ and $\mathrm{C}$ show the results of the interactions between the symmetric systems, $\mathrm{C} 8-\mathrm{C} 8, \mathrm{NH}_{2}-$ $\mathrm{NH}_{2}$, and $\mathrm{SH}-\mathrm{SH}$, and long-ranged repulsive forces, which can be fitted by the electrical double-layer force, are observed in all three cases. For the C8-C8 systems in $1 \mathrm{mM} \mathrm{NaCl}$, a short-ranged attraction attributed to hydrophobic interactions between the alkyl chains and this is also observed in $\mathrm{CaCl}_{2}$. For the $\mathrm{NH}_{2}-\mathrm{NH}_{2}$ system, the force is also repulsive in the entire measured range. However, for the $\mathrm{SH}-\mathrm{SH}$ system, the repulsive force is replaced by an attraction at a separation distance of approximately $4 \mathrm{~nm}$, and we assign this to a bridging force mediated by $\mathrm{Ca}^{2+}$ adsorbed to the $\mathrm{SH}$ surfaces. This adsorption of $\mathrm{Ca}^{2+}$ is further evidenced by the huge drop in surface potential observed when going from $\mathrm{NaCl}$ to $\mathrm{CaCl}_{2}$. A drop of a similar magnitude is not observed for the $\mathrm{NH}_{2}$ surface and thus cannot solely be explained by the increased ionic strength. For the C8-C8 systems, a significant drop in surface potential is also found, but no indication of bridging forces induced by $\mathrm{Ca}^{2+}$ is observed here. We suggest that this is related to the difference between having $\mathrm{Ca}^{2+}$ adsorbed to the inner or the outer charge layer, and we will return to this when we discuss the results of the retraction force curves.

Figure 4D, E and $\mathrm{F}$ show the forces between the asymmetric systems, $\mathrm{C} 8-\mathrm{NH}_{2}, \mathrm{C} 8-\mathrm{SH}$ and $\mathrm{SH}-\mathrm{NH}_{2}$. For the $\mathrm{C} 8-\mathrm{NH}_{2}$ system, the force curve is dominated by a long-ranged repulsion that is in qualitative agreement with the expected double-layer interaction between two oppositely charged surfaces. As in the case of the $\mathrm{C} 8-\mathrm{NH}_{2}$ system in $\mathrm{NaCl}$, the surface potentials are, in the presence of $\mathrm{CaCl}_{2}$, identical to the values obtained for the symmetric systems, which indicates that no significant extra charge regulation is taking place. For the $\mathrm{C} 8-\mathrm{SH}$ system, the attraction interpreted as $\mathrm{Ca}^{2+}$ induced 
bridging forces are observed at a separation shorter than $10 \mathrm{~nm}$, while only a weak interaction is observed at larger separation. However, the long-ranged forces are in apparent agreement with a weak double-layer repulsion found by using the values for the surface potential found for the symmetric systems. Finally, for the $\mathrm{SH}-\mathrm{NH}_{2}$ system, a long-ranged attraction, which is in qualitative agreement with the expectation for the double-layer interaction between two oppositely charged surfaces is observed. For the $\mathrm{SH}-\mathrm{NH}_{2}$ system, the calculated surface potentials in $\mathrm{CaCl}_{2}$ are also significantly higher than the values found for the symmetric systems, and the interaction also here seems to be better described by the constant potential boundary conditions than by the constant charge boundary conditions. This again suggests a strong extra charge regulation when these surfaces with oppositely charged outer layers are approaching each other.

\subsection{Adhesion forces}

Figure 5 and 6 show representative retraction force curves for the symmetric systems and asymmetric systems, measured in $1 \mathrm{mM} \mathrm{NaCl}$ solution and in $1 \mathrm{mM} \mathrm{CaCl}_{2}$ solution, respectively, while the mean adhesion forces based on 70 consecutive force curves are provided in Table 4 . In the following, we will compare the adhesion in $\mathrm{NaCl}$ and in $\mathrm{CaCl}_{2}$ for each set of surfaces and discuss the results in relation to the approach force curves for the same systems.

For the C8-C8 system, a strong adhesion is observed in both $\mathrm{NaCl}$ and in $\mathrm{CaCl}_{2}$ that is in agreement with the short-ranged hydrophobic attraction observed in the approach force curves. The mean adhesion force is slightly higher in $\mathrm{CaCl}_{2}$ compared to in $\mathrm{NaCl}$, which might indicate a small contribution from ion bridging to the total adhesion force. However, as discussed in relation to the approach force curve, we speculate that ion bridging is hampered by the fact that $\mathrm{Ca}^{2+}$ is adsorbing to the inner charge layer and that ion bridging thus is sterically hindered by the alkyl chains. For the two other symmetric systems, we observe rather different results. For the $\mathrm{NH}_{2}-\mathrm{NH}_{2}$ system where the surfaces are positively charged and no $\mathrm{Ca}^{2+}$ adsorption is expected, the forces in both $\mathrm{NaCl}$ and in $\mathrm{CaCl}_{2}$ are purely repulsive and no adhesion is observed. For the $\mathrm{SH}-\mathrm{SH}$ system, the forces in $\mathrm{NaCl}$ are purely repulsive and no adhesion is observed. However, in $\mathrm{CaCl}_{2}$ where the drop in surface potential indicated $\mathrm{Ca}^{2+}$ adsorption, ion bridging is now also observed in terms of significant contact adhesion. In addition to the contact adhesion, some more long-ranged secondary adhesion events are also observed. We interpret these secondary adhesion events as an indication that some degree of polymerization in the silane layer has occurred during the surface modification.

Finally, we have the three asymmetric systems, C8- $\mathrm{NH}_{2}, \mathrm{C} 8-\mathrm{SH}$ and $\mathrm{SH}-\mathrm{NH}_{2}$, where both nonspecific binding, electrostatic interactions and ion bridging are involved. For the $\mathrm{C} 8-\mathrm{NH}_{2}$ system, we observe a relatively strong and similar contact adhesion in $\mathrm{NaCl}$ and $\mathrm{CaCl}_{2}$. Based on the knowledge about the surface chemistries and the long-ranged attraction observed in the approach force curves, we expect this adhesion to be mainly of electrostatic origin but with some contribution from nonspecific binding between the alkyl chains and the $\mathrm{NH}_{2}$-silane surface. No ion bridging is expected or observed for this system. For the $\mathrm{C} 8-\mathrm{SH}$ system in $\mathrm{NaCl}$, a weak contact adhesion is observed despite the purely responsive force observed in the approach force curve. We assign this adhesion to nonspecific binding between the alkyl chains and the $\mathrm{SH}$-silane surface. While the mean value of the contact adhesion is not increased in $\mathrm{CaCl}_{2}$, clear secondary adhesion events that indicate ion bridging between polymerized $\mathrm{SH}$-silane and the $\mathrm{C} 8$ surface are observed. For the $\mathrm{SH}-\mathrm{NH}_{2}$ system in $\mathrm{NaCl}$, a strong contact adhesion that is expected to mainly be of electrostatic origin is observed. In the 
presence of $\mathrm{CaCl}_{2}$ a slightly stronger contact adhesion and clear secondary adhesion events are observed, although one should not expect ion bridging between a positively and a negative charged surface. However, here we recall that the $\mathrm{NH}_{2}$ surface might consist of a positively charged outer layer and a negatively charged inner layer. Thus, ion bridging might occur between the outer charged layers of the $\mathrm{SH}$ surface and the inner charged layer of the $\mathrm{NH}_{2}$ surface at the same time as direct electrostatic interactions are taking place between the two outer charged layers.

\section{$1 \mathrm{mM} \mathrm{NaCl}$}
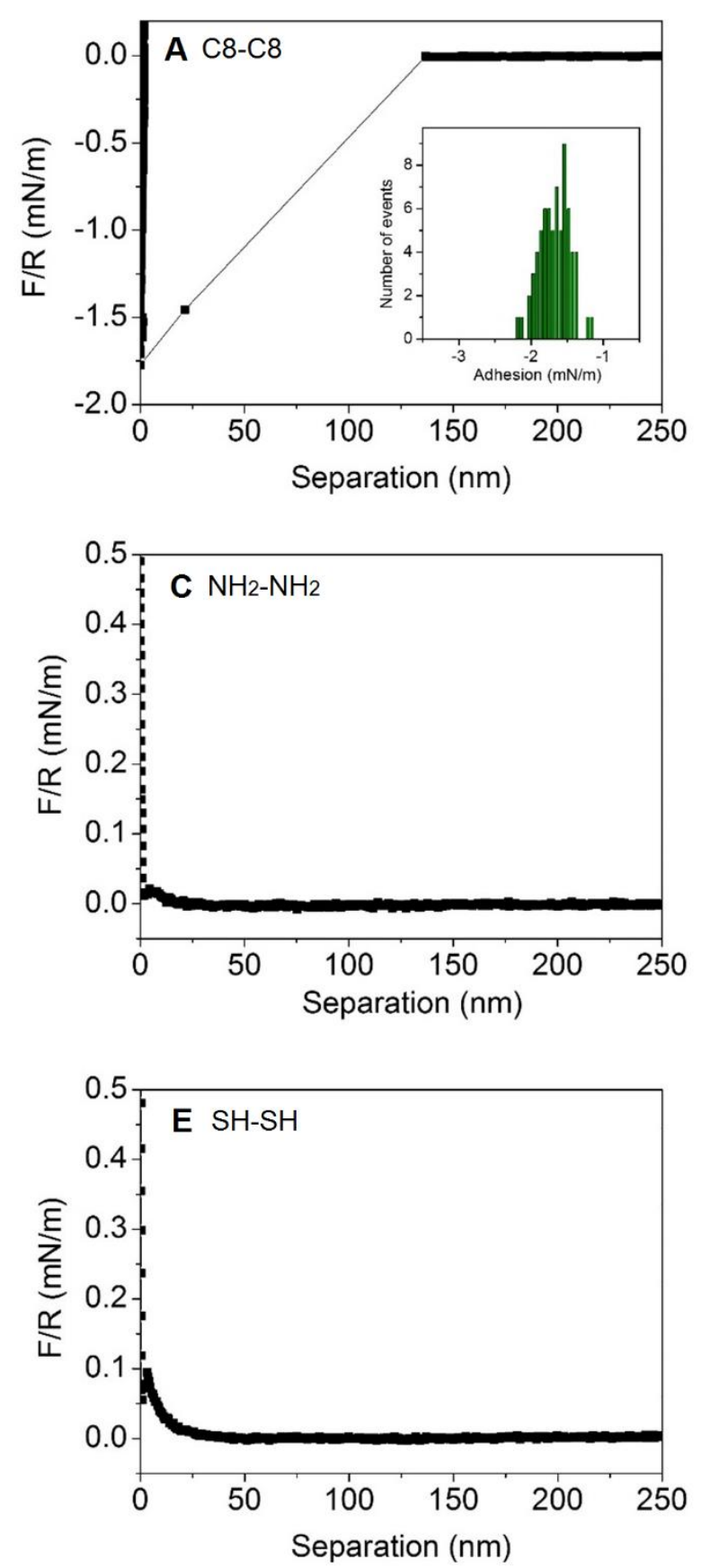

$1 \mathrm{mM} \mathrm{CaCl}_{2}$
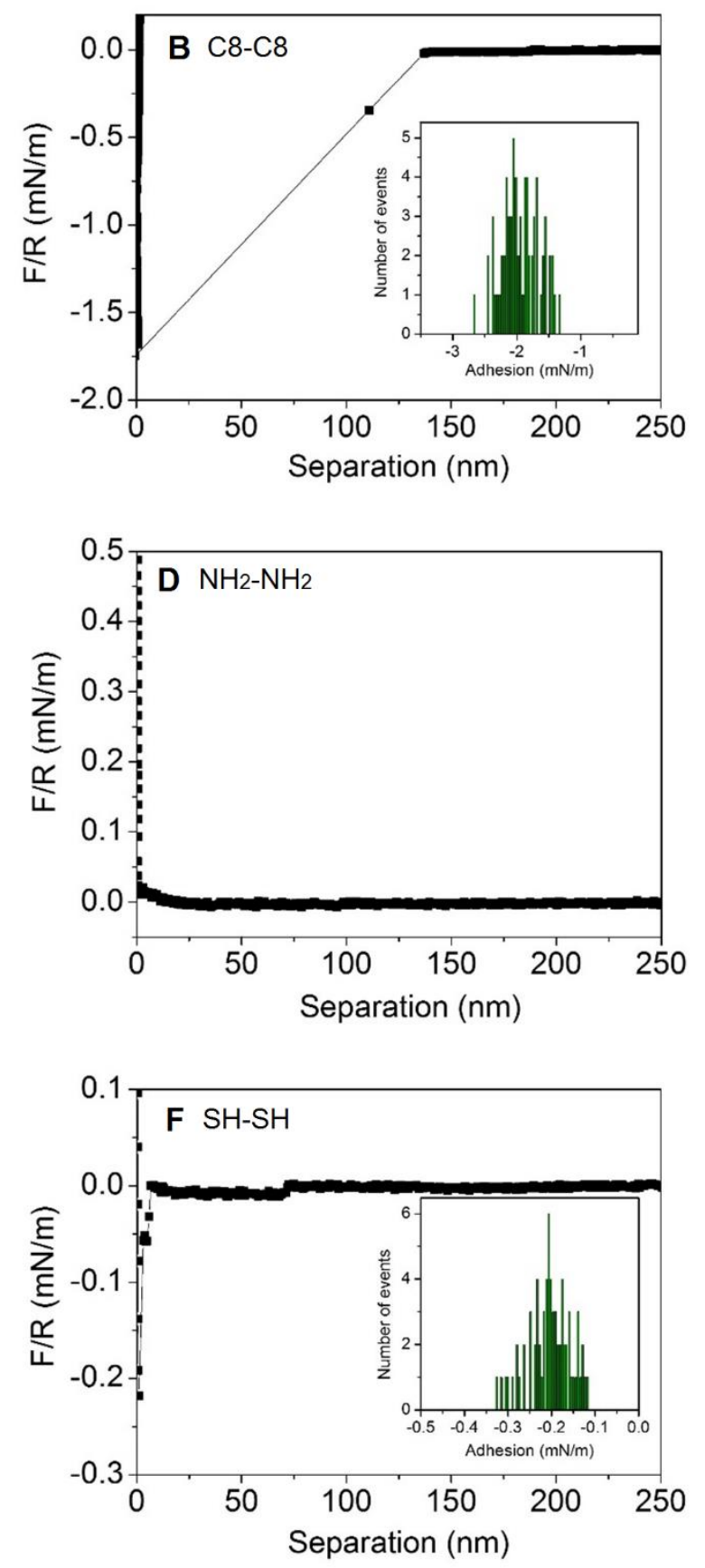
Figure 5. Retraction force curves for the surface pairs: C8-C8 (A), $\mathrm{NH}_{2}-\mathrm{NH}_{2}(\mathrm{C}), \mathrm{SH}-\mathrm{SH}$ (E) across $1 \mathrm{mM} \mathrm{NaCl}$ (left), and C8-C8 (B), $\mathrm{NH}_{2}-\mathrm{NH}_{2}$ (D), $\mathrm{SH}-\mathrm{SH}$ (F) across $1 \mathrm{mM} \mathrm{CaCl}$ (right). 70 force curves were collected in each system. The inset shows the number of events vs. adhesion forces.

\section{$1 \mathrm{mM} \mathrm{NaCl}$}
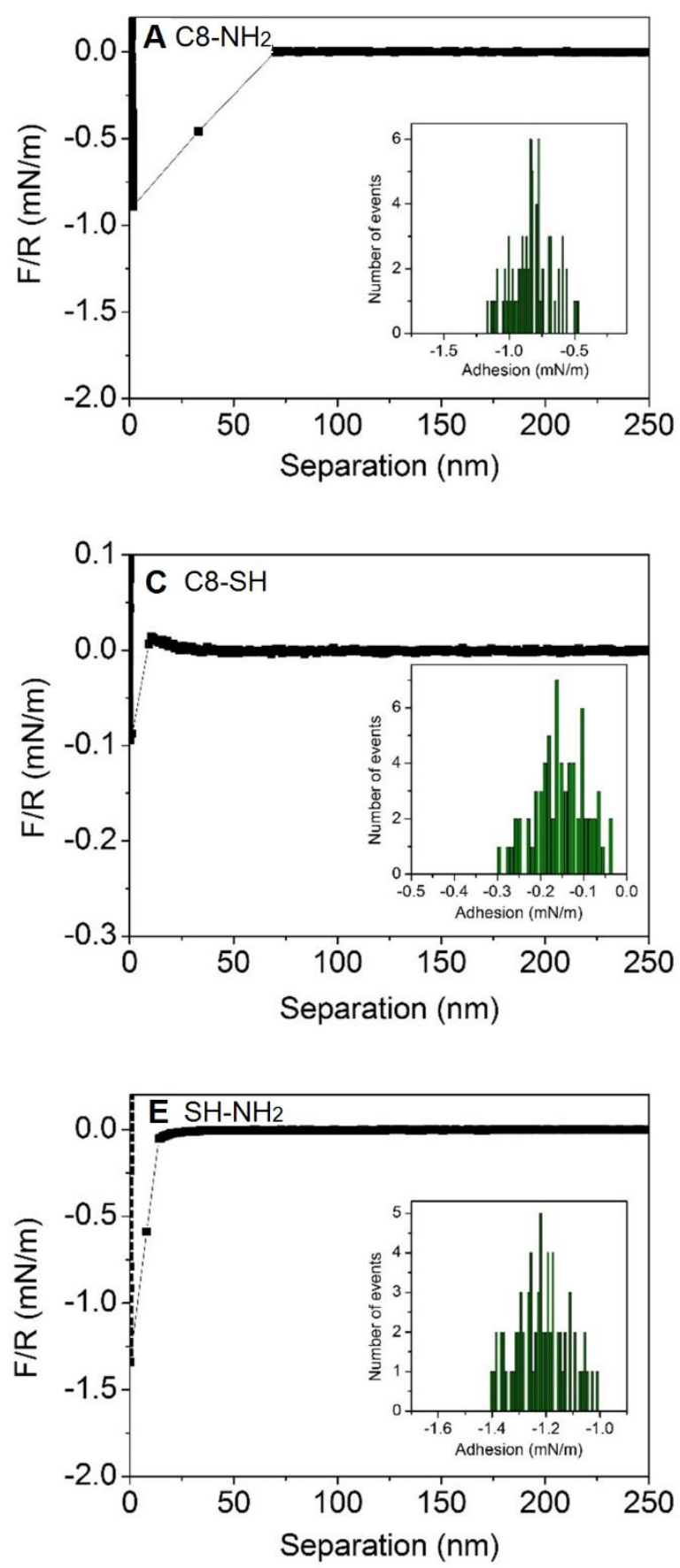

\section{$1 \mathrm{mM} \mathrm{CaCl}_{2}$}
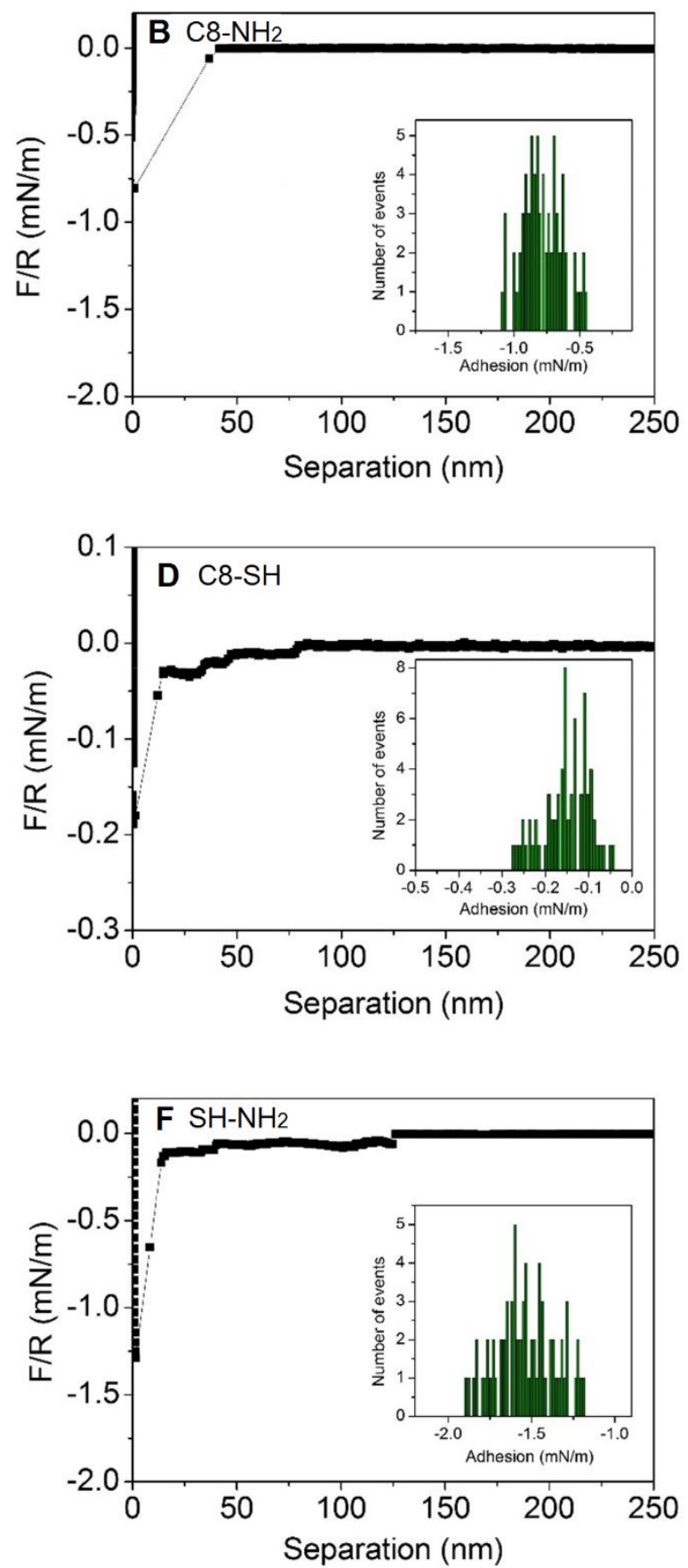

Figure 6. Retraction force curves for the surface pairs: C8- $\mathrm{NH}_{2}(\mathrm{~A}), \mathrm{C} 8-\mathrm{SH}(\mathrm{C}), \mathrm{SH}_{-} \mathrm{NH}_{2}$ (E) across $1 \mathrm{mM} \mathrm{NaCl}$ (left), and C8-NH 2 (B), C8-SH (D), $\mathrm{SH}-\mathrm{NH}_{2}$ (F) across $1 \mathrm{mM} \mathrm{CaCl}_{2}$ (right). 70 force curves were collected in each system. The inset shows number of events vs. adhesion forces. 
Table 4. Mean values of the adhesion forces (in units of $(\mathrm{mN} / \mathrm{m})$ ) in $1 \mathrm{mM} \mathrm{NaCl}$ and $1 \mathrm{mM} \mathrm{CaCl}_{2}$. The mean values are based on values from 70 individual force curves and the uncertainties represent the standard deviations.

\begin{tabular}{|l|c|c|c|c|c|c|}
\hline & $\mathrm{C} 8-\mathrm{C} 8$ & $\mathrm{NH}_{2}-\mathrm{NH}_{2}$ & $\mathrm{SH}-\mathrm{SH}$ & $\mathrm{C} 8-\mathrm{NH}_{2}$ & $\mathrm{C} 8-\mathrm{SH}$ & SH-NH \\
\hline $1 \mathrm{mM} \mathrm{NaCl}$ & $-1.7 \pm 0.12$ & 0 & 0 & $-0.83 \pm 0.22$ & $-0.17 \pm 0.03$ & $-1.32 \pm 0.10$ \\
& & & & & & \\
\hline $1 \mathrm{mM} \mathrm{CaCl}_{2}$ & $-1.97 \pm 0.15$ & 0 & $-0.21 \pm 0.02$ & $-0.81 \pm 0.18$ & $-0.15 \pm 0.02$ & $-1.54 \pm 0.12$ \\
\hline
\end{tabular}

\section{Summary and Conclusions}

In this study, we have prepared three different silane based monolayers on silica particles attached to AFM cantilevers and on flat silica substrates. The trimethoxy(octyl)silane (C8) monolayer is apolar, but the surface layer carries an effective negative charge in water due to dissociation of unreacted hydroxyl groups on the silica surface. In this work, we are referring to these charges sitting behind the monolayer as the inner charge layer. The (3-aminopropyl)trimethoxysilane $\left(\mathrm{NH}_{2}\right)$ and the (3mercaptopropyl)trimethoxysilane $(\mathrm{SH})$ monolayers are carrying positive and negative effective charges, respectively, as a result of ionization of the functional group in the two monolayers. However, for these two surfaces we note that the total effective charge might be composed of inner and outer charged layers, which means the $\mathrm{NH}_{2}$ surface can be expected to carry both positive charges (in the outer charged layer) and negative charges (in the inner charged layer), while the SH surface can be expected to carry negative charges both in the outer and in the inner charged layers.

Next, we measured the surface forces between the three symmetric systems (similar surfaces) and the three asymmetric systems (dissimilar surfaces) in $1 \mathrm{mM} \mathrm{NaCl}$ and in $1 \mathrm{mM} \mathrm{CaCl}_{2}$, and in the analysis of the force curves we focused on the long-ranged electrical double-layer forces and the short-ranged adhesion forces. In this experiment, we observed repulsive double-layer forces for the three symmetric systems (C8-C8, $\mathrm{NH}_{2}-\mathrm{NH}_{2}$ and $\left.\mathrm{SH}-\mathrm{SH}\right)$ and for the asymmetric system, $\mathrm{C} 8-\mathrm{SH}$, in both 1 $\mathrm{mM} \mathrm{NaCl}$ and in $1 \mathrm{mM} \mathrm{CaCl}_{2}$. For all the cases, the experimental force curves were between the double-layer forces calculated with constant potential boundary conditions and the double-layer forces calculated with constant surface charge boundary conditions, which means that both the surface charges and the surface potentials are regulated as the surfaces are approaching each other. We also observed double-layer forces corresponding to significantly lower surface potentials in 1 $\mathrm{mM} \mathrm{CaCl}_{2}$ compared to in $1 \mathrm{mM} \mathrm{NaCl}$, which indicates adsorption of calcium ions to the $\mathrm{C} 8$ and $\mathrm{SH}$ surfaces. For the two remaining asymmetric systems $\left(\mathrm{C} 8-\mathrm{NH}_{2}\right.$ and $\left.\mathrm{SH}-\mathrm{NH}_{2}\right)$ we observed attractive double-layer forces both in $1 \mathrm{mM} \mathrm{NaCl}$ and in $1 \mathrm{mM} \mathrm{CaCl}_{2}$. In this instance, it was interestingly observed that when the experimental force curves were compared to the calculated double-layer forces, the surface potential of the $\mathrm{C} 8$ and the $\mathrm{NH}_{2}$ surfaces in the $\mathrm{C} 8-\mathrm{NH}_{2}$ system were identical to the surface potentials found for the symmetric systems $\mathrm{C} 8-\mathrm{C} 8$ and $\mathrm{NH}_{2}-\mathrm{NH}_{2}$, while the surface potentials for the $\mathrm{SH}$ and $\mathrm{NH}_{2}$ surfaces in the $\mathrm{SH}-\mathrm{NH}_{2}$ system were significantly larger than found in the symmetric systems $\mathrm{SH}-\mathrm{SH}$ and $\mathrm{NH}_{2}-\mathrm{NH}_{2}$. Further, the functional form of the experimentally observed double-layer force for the $\mathrm{SH}-\mathrm{NH}_{2}$ system appear to be much better described by a doublelayer force calculated using constant potential boundary conditions than by a double-layer force 
calculated using constant surface charge boundary conditions. These observations indicate that a significant extra charge regulation is taking place in the case of interaction between oppositely charged outer charge layers.

From the signs of the surface charge, adsorption of calcium ions were expected for the $\mathrm{C} 8$ and $\mathrm{SH}$ surfaces which were confirmed by the significant decrease in surface potential observed for the C8$\mathrm{C} 8$ and the $\mathrm{SH}-\mathrm{SH}$ systems when going from $1 \mathrm{mM} \mathrm{NaCl}$ to $1 \mathrm{mM} \mathrm{CaCl}_{2}$. Thus, based on this simple consideration, ion bridging forces in the presence of calcium ions could be expected for the $\mathrm{C} 8 \mathrm{C} 8$, $\mathrm{SH}-\mathrm{SH}$ and $\mathrm{C} 8-\mathrm{SH}$ systems but not for the $\mathrm{NH}_{2}-\mathrm{NH}_{2}, \mathrm{C} 8-\mathrm{NH}_{2}$ and $\mathrm{NH}_{2}-\mathrm{SH}$ systems. In agreement with these expectations, we observe a clear indication of ion bridging forces for the $\mathrm{SH}-\mathrm{SH}$ and C8$\mathrm{SH}$ systems and a weak indication of ion bridging forces for the C8-C8 system, and we speculate that ion bridging forces mediated by adsorption of calcium ions to the inner charge layer are sterically hindered by the alkyl chains on the $\mathrm{C} 8$ surface. Further, as expected, we do not observe ion bridging forces for the $\mathrm{NH}_{2}-\mathrm{NH}_{2}$ and the $\mathrm{C} 8-\mathrm{NH}_{2}$ systems, while we do observe ion bridging for the $\mathrm{NH}_{2}-\mathrm{SH}$ system. In this study, we should recall that the $\mathrm{NH}_{2}$ surface consists of a positively charged outer layer and a negatively charged inner layer. Thus, we suggest that some degree of ion bridging can occur between the inner charged layer on the $\mathrm{NH}_{2}$ surface and outer charged layer on the $\mathrm{SH}$ surface.

Based on our results, we suggest that measurements of surface forces between surfaces with different functional groups in the presence of ions with different valency can be used as a physical tool for qualitative identification of the presence of different functional groups on the surfaces and thus work as a supplement to spectroscopic tools where direct chemical information can be obtained.

\section{Acknowledgments}

The research leading to these results has received funding from the Danish Hydrocarbon Research and Technology Centre (Centre for Oil and Gas - DTU) under the Advanced Water Flooding programme.

\section{References}

(1) Claesson, P. M.; Herder, P. C.; Blom, C. E.; Ninham, B. W. Interactions between a positively charged hydrophobic surface and a negatively charged bare mica surface. J. Colloid Interface Sci. 1987, $118,68-79$.

(2) Salles, F.; Douillard, J.-M.; Bildstein, O.; El Ghazi, S.; Prélot, B.; Zajac, J.; Van Damme, H.

Diffusion of Interlayer Cations in Swelling Clays as a Function of Water Content: Case of Montmorillonites Saturated with Alkali Cations. J. Phys. Chem. C. 2015, 119, 10370-10378. 
(3) Liu, X.; Yan, W.; Stenby, E. H.; Thormann, E. Release of Crude Oil from Silica and Calcium Carbonate Surfaces: On the Alternation of Surface and Molecular Forces by High- and LowSalinity Aqueous Salt Solutions. Energy Fuels 2016, 30, 3986-3993.

(4) Valleau, J. P.; Ivkov, R.; Torrie, G. M. Colloid stability: The forces between charged surfaces in an electrolyte. J. Chem. Phys. 1991, 95, 520-532.

(5) Liu, X.; Dedinaite, A.; Rutland, M.; Thormann, E.; Visnevskij, C.; Makuska, R.; Claesson, P. M. Electrostatically Anchored Branched Brush Layers. Langmuir 2012, 28, 15537-15547.

(6) Liu, X.; Dedinaite, A.; Nylander, T.; Dabkowska, A. P.; Skoda, M.; Makuska, R.; Claesson, P. M. Association of anionic surfactant and physisorbed branched brush layers probed by neutron and optical reflectometry. J. Colloid Interface Sci. 2015, 440, 245-252.

(7) Rajan, R.; Hayashi, F.; Nagashima, T.; Matsumura, K. Toward a Molecular Understanding of the Mechanism of Cryopreservation by Polyampholytes: Cell Membrane Interactions and Hydrophobicity. Biomacromolecules 2016, 17, 1882-1893.

(8) B.V. Derjaguin; Landau, L. Theory of the stability of strongly charged lyophobic sols and of the adhesion of strongly charged particles in solution of electrolytes. Acta Physicochim. URSS 1941, $14,633-62$.

(9) Verwey, E. J. W.; Overbeek, J. T. G. Theory of the Stability of Lyophobic Colloids. Elsevier Publishing Co, Amsterdam 1948.

(10) Israelachvili, J. Intermolecular and Surface Forces. Academic Press, London 1992.

(11) Pashley, R. M. Forces between mica surfaces in La3+ and Cr3+ electrolyte solutions. J. Colloid Interface Sci. 1984, 102, 23-35.

(12) Besteman, K.; Zevenbergen, M. A. G.; Heering, H. A.; Lemay, S. G. Direct Observation of Charge Inversion by Multivalent Ions as a Universal Electrostatic Phenomenon. Phys. Rev. Lett. 2004, 93, 170802.

(13) Love, J. C.; Estroff, L. A.; Kriebel, J. K.; Nuzzo, R. G.; Whitesides, G. M. Self-Assembled Monolayers of Thiolates on Metals as a Form of Nanotechnology. Chem. Rev. 2005, 105, 11031170.

(14) Maroni, P.; Montes Ruiz-Cabello, F. J.; Cardoso, C.; Tiraferri, A. Adsorbed Mass of Polymers on Self-Assembled Monolayers: Effect of Surface Chemistry and Polymer Charge. Langmuir 2015, $31,6045-6054$.

(15) Christenson, H. K.; Claesson, P. M. Direct measurements of the force between hydrophobic surfaces in water. Adv. Colloid Interface Sci. 2001, 91, 391-436. 
(16) Ederth, T.; Claesson, P.; Liedberg, B. Self-Assembled Monolayers of Alkanethiolates on Thin Gold Films as Substrates for Surface Force Measurements. Long-Range Hydrophobic Interactions and Electrostatic Double-Layer Interactions. Langmuir 1998, 14, 4782-4789.

(17) Hu, K.; Bard, A. J. Use of Atomic Force Microscopy for the Study of Surface Acid-Base Properties of Carboxylic Acid-Terminated Self-Assembled Monolayers. Langmuir 1997, 13, 51145119.

(18) Wasserman, S. R.; Tao, Y. T.; Whitesides, G. M. Structure and reactivity of alkylsiloxane monolayers formed by reaction of alkyltrichlorosilanes on silicon substrates. Langmuir 1989, 5, 1074-1087.

(19) Haensch, C.; Hoeppener, S.; Schubert, U. S. Chemical modification of self-assembled silane based monolayers by surface reactions. Chem. Soc. Rev. 2010, 39, 2323-2334.

(20) Wang, Y.; Lieberman, M. Growth of Ultrasmooth Octadecyltrichlorosilane Self-Assembled Monolayers on SiO2. Langmuir 2003, 19, 1159-1167.

(21) An, Y.; Chen, M.; Xue, Q.; Liu, W. Preparation and self-assembly of carboxylic acidfunctionalized silica. J. Colloid Interface Sci. 2007, 311, 507-513.

(22) Adamkiewicz, M.; O'Hara, T.; O'Hagan, D.; Hähner, G. A vapor phase deposition of selfassembled monolayers: Vinyl-terminated films of volatile silanes on silicon oxide substrates. Thin Solid Films 2012, 520, 6719-6723.

(23) Ducker, W. A.; Senden, T. J.; Pashley, R. M. Direct measurement of colloidal forces using an atomic force microscope. Nature 1991, 353, 239-241.

(24) Butt, H.-J.; Cappella, B.; Kappl, M. Force measurements with the atomic force microscope: Technique, interpretation and applications. Surf. Sci. Rep. 2005, 59, 1-152.

(25) Toikka, G.; Hayes, R. A.; Ralston, J. Surface Forces between Spherical ZnS Particles in Aqueous Electrolyte. Langmuir 1996, 12, 3783-3788.

(26) Green, C. P.; Lioe, H.; Cleveland, J. P.; Proksch, R.; Mulvaney, P.; Sader, J. E. Normal and torsional spring constants of atomic force microscope cantilevers. Rev. Sci. Instrum. 2004, 75, 1988-1996.

(27) Sader, J. E.; Chon, J. W. M.; Mulvaney, P. Calibration of rectangular atomic force microscope cantilevers. Rev. Sci. Instrum. 1999, 70, 3967-3969.

(28) Dunér, G.; Iruthayaraj, J.; Daasbjerg, K.; Pedersen, S. U.; Thormann, E.; Dėdinaitè, A. Attractive double-layer forces and charge regulation upon interaction between electrografted amine layers and silica. J. Colloid Interface Sci. 2012, 385, 225-234. 
(29) Bergström, L. Hamaker constants of inorganic materials. Adv. Colloid Interface Sci. 1997, 70, 125-169.

(30) Thormann, E. Surface forces between rough and topographically structured interfaces. Curr. Opin. Colloid Interface Sci. 2017, 27, 18-24.

(31) Tanaka, M.; Sawaguchi, T.; Kuwahara, M.; Niwa, O. Surface Modification of Silicon Oxide with Trialkoxysilanes toward Close-Packed Monolayer Formation. Langmuir 2013, 29, 6361-6368. (32) Tian, R.; Seitz, O.; Li, M.; Hu, W.; Chabal, Y. J.; Gao, J. Infrared Characterization of Interfacial Si-O Bond Formation on Silanized Flat SiO2/Si Surfaces. Langmuir 2010, 26, 45634566.

(33) Aissaoui, N.; Bergaoui, L.; Landoulsi, J.; Lambert, J.-F.; Boujday, S. Silane Layers on Silicon Surfaces: Mechanism of Interaction, Stability, and Influence on Protein Adsorption. Langmuir 2012, 28, 656-665.

(34) Thormann, E.; Simonsen, A. C.; Hansen, P. L.; Mouritsen, O. G. Force Trace Hysteresis and Temperature Dependence of Bridging Nanobubble Induced Forces between Hydrophobic Surfaces. ACS Nano 2008, 2, 1817-1824.

(35) Hansson, P. M.; Swerin, A.; Schoelkopf, J.; Gane, P. A. C.; Thormann, E. Influence of Surface Topography on the Interactions between Nanostructured Hydrophobic Surfaces. Langmuir 2012, 28, 8026-8034.

(36) Liu, C.; Thormann, E.; Tyrode, E.; Claesson, P. M. Charge regulation and energy dissipation while compressing and sliding a cross-linked chitosan hydrogel layer. J. Colloid Interface Sci. 2015, 443, 162-169.

(37) Ederth, T.; Claesson, P. M. Forces between Carboxylic Acid Surfaces in Divalent Electrolyte Solutions. J. Colloid Interface Sci. 2000, 229, 123-128. 